\title{
Strategi Pengembangan Kawasan Wisata Pantai Songka Di Kota Palopo
}

\author{
Muhammad Bibin ${ }^{\mathrm{a}, 1, *}$, Ani Ardian ${ }^{\mathrm{b}, 2}$ \\ ${ }^{a}$ Universitas Muhammadiyah Sidenreng Rappang, Rappang, 91651, Indonesia \\ ${ }^{b}$ Universitas Muhammadiyah Sidenreng Rappang, Rappang, 91651, Indonesia \\ ${ }^{1}$ muhbibin@umsrappang.ac.id ; ${ }^{2}$ aniardian@umsrappang.ac.id \\ *Corresponding author
}

ARTICLE INFO

Article history:

Submitted: May 22, 2020

Reviewed: June 10, 2020

Accepted: June 18, 2020

Published: June 30, 2020

Keywords: Tourism, Policy, Songka Beach.

\section{ABSTRACT}

Palopo City has coastal tourism potential that can be utilized. One of the coastal areas in Palopo City that has the potential to be a coastal tourist attraction is Songka Beach. But the problem in the Songka Beach Tourism Area is the lack of visitor interest on a typical day. This is due to the Songka Beach tourism area has not been developed optimally either by the community around the tourist attraction or the local government as well as the lack of tourism promotion. The facilities and infrastructure that can support the development of Songka Beach attractions are somewhat lacking. The purpose of this research is to design a strategy for developing Songka Beach tourism object so that it can benefit more optimally. The analysis used to determine the right strategy in developing Songka Beach is to use a process hierarchy analysis (AHP). Based on the results of research on ecological aspects which are the first priority in the development of Songka Beach tourism and strategies that are prioritized in the development of the Songka Beach Tourism Area are making the suitability map of Songka Beach tourism and calculating the carrying capacity of the tourist area with the aim that there are restrictions on the number of visitors who want to visit the area Songka Beach tourism so that the preservation of natural resources is maintained and not damaged.

\section{ABSTRAK}

Kota Palopo memiliki potensi wisata pesisir yang bisa dimanfaatkan. Salah satu kawasan pesisir yang ada di Kota Palopo yang berpotensi untuk dijadikan objek wisata pesisir adalah Pantai Songka. Namun permasalahan yang ada di Kawasan Wisata Pantai Songka adalah kurangnya minat pengunjung pada hari-hari biasa. Hal ini disebabkan kawasan wisata Pantai Songka belum dikembangkan secara optimal baik oleh masyarakat sekitar objek wisata maupun pemerintah daerah serta kurangnya promosi wisata. Sarana dan prasarana yang dapat mendukung pengembangan objek wisata Pantai Songka pun terbilang masih kurang. Tujuan dari penelitian ini adalah untuk merancang strategi pengembangan objek wisata Pantai Songka agar bermanfaat lebih optimal. Analisis yang digunakan untuk menentukan strategi yang tepat dalam pengembangan Pantai Songka adalah dengan menggunakan analisis hirarki proses (AHP). Berdasarkan hasil penelitian aspek ekologi yang menjadi prioritas pertama dalam pengembangan wisata Pantai Songka serta strategi yang menjadi prioritas dalam pengembangan Kawasan Wisata Pantai Songka adalah pembuatan peta kesesuaian wisata Pantai Songka dan menghitung daya dukung kawasan wisata dengan tujuan agar ada 
Kata Kunci: Wisata, Kebijakan, Pantai Songka. pembatasan jumlah pengunjung yang ingin berkunjung di kawasan wisata Pantai Songka sehingga kelestarian sumberdaya alam tetap terjaga dan tidak mengalami kerusakan.

Copyright (C) 2019 Politeknik Negeri Samarinda. All rights reserved.

\section{Pendahuluan}

Wilayah pesisir merupakan tempat pertemuan antara daratan dan lautan. Wilayah pesisir memiliki potensi untuk meningkatkan devisa Negara yaitu dapat dimanfaatkan untuk kepentingan wisata (Dahuri, 2003). Sektor wisata pada umumnya diarahkan sebagai sektor andalan untuk mendorong pertumbuhan ekonomi, peningkatan pendapatan daerah, memberdayakan perekonomian masyarakat, memperluas lapangan kerja dan kesempatan berusaha, serta meningkatkan pengenalan dan pemasaran produk dalam rangka meningkatkan kesejahteraan masyarakat.

Salah satu kegiatan wisata pesisir di Indonesia adalah wisata pantai. Wisata pantai merupakan suatu bentuk kegiatan wisata yang umumnya memanfaatkan sumberdaya pantai (Sobari et al. 2006). Salah satu kategori wisata pantai adalah rekreasi pantai yang merupakan kegiatan rekreasi dengan memanfaatkan sumberdaya pantai seperti pasir putih, pemandangan, hamparan pantai dan perairan pantainya (Yulianda et al. 2010).

Kota Palopo memiliki potensi wisata pesisir yang bisa dimanfaatkan. Salah satu kawasan pesisir yang ada di Kota Palopo yang berpontensi untuk dijadikan objek wisata pesisir adalah Pantai Songka. Pemerintah Kota Palopo telah menetapkan Pantai Songka sebagai destinasi wisata. Pantai Songka mempunyai karakteristik pantai berpasir putih ditunjang dengan panorama alam pantai yang cukup eksotik ke arah Teluk Bone. Kunjungan wisatawan ke Pantai Songka masih dipengaruhi oleh harihari tertentu, misalnya hari libur sekolah, hari-hari besar dan hari libur lainnya. Puncak pengunjung yang dating berkunjung ke Pantai Songka adalah ketika hari Raya Idul Fitri.

Kawasan wisata Pantai Songka pada harihari biasa masih relative sepi, hal ini disebabkan kawasan wisata Pantai Songka belum dikembangkan secara optimal baik oleh masyarakat sekitar objek wisata dan pemerintah daerah. Sarana dan prasarana yang dapat mendukung pengembangan objek wisata Pantai Songka masih kurang, masih kurangnya promosi wisata yang berkesinambungan kepada masyarakat luas, dan kebanyakan hanya melaluiminformasi dari mulut ke mulut serta belum optimalnya keterlibatan stakeholder dalam hal koordinasi dan kerja sama. Dalam melaksanakan konsep pengembangan wisata tentunya diperlukan partisipasi yang cukup baik dari para stakeholder. Hubungan antar organisasi, kolaborasi dan kerjasama dalam pengembangan wisata merupakan suatu hal yang penting (Christopher, 2011). Perlunya strategi pengembangan objek wisata Pantai Songka agar dapat bermanfaat lebih optimal, dapat memberi peluang lapangan kerja baru di bidang wisata bagi masyarakat sekitar objek wisata serta menjadikan Pantai Songka objek wisata andalan yang akan menarik banyak pengunjung dan dapat menjadi objek pendukung bagi objek-objek wisata lain yang sudah berkembang di Kota Palopo.

\section{Review Tinjauan Pustaka}

\section{a. Wilayah Pesisir}

Dahuri et al. (1996) menyatakan definisi wilayah pesisir yang digunakan di Indonesia adalah pertemuan antara darat dan laut; ke arah darat wilayah pesisir meliputi bagian daratan, baik kering maupun terendam air, yang masih dipengaruhi sifat-sifat laut seperti pasang surut, angin laut dan perembesan air asin; sedangkan ke arah laut wilayah pesisir mencakup bagian laut yang masih dipengaruhi oleh proses-prsoes alami yang terjadi di darat seperti sedimentasi dan aliran air tawar, maupun yang disebabkan oleh kegiatan manusia di darat seperti penggundulan hutan dan pencemaran. 
Wilayah pesisir didefinisikan sebagai wilayah di mana daratan berbatasan dengan laut; batas di daratan meliputi daerah-daerah yang tergenang air maupun yang tidak tergenang air yang masih dipengaruhi oleh proses-proses laut seperti pasang surut, angin laut, dan intrusi garam; sedangkan batas di laut ialah daerah-daerah yang dipengaruhi oleh proses-proses alami di daratan seperti sedimentasi dan mengalirnya air tawar ke laut, serta daerah-daerah laut yang dipengaruhi oleh kegiatan-kegiatan manusia di daratan (Bengen, 2001).

\section{b. Pantai berpasir}

Pantai pasir terdiri dari kwarsa dan feldspar, bagian yang paling banyak dan paling keras sisi-sisa pelapukan batu di gunung. Di daerah tertentu lainnya, sisa-sisa pecahan terumbu karang yang dominan. Pantai yang berpasir dibatasi hanya di daerah di mana gerakan air yang kuat mengangkut partikel-partikel yang halus dan ringan. Parameter lingkungan yang berpengaruh di pantai pasir adalah pola arus yang mengangkut pasir halus, gelombang yang melepaskan energinya ke pantai, serta angin yang menerbangkan pasir halus yang kering dan memindahkannya ke tempat lain (Dahuri et al., 1996).

\section{c. Pantai Berbatu}

Pantai berbatu merupakan satu dari lingkungan pesisir dan laut yang cukup subur di mana pantai yang berbatu-batu memanjang ke laut dan terbenam di air. Kombinasi substrat keras untuk penempelan, seringnya aksi gelombang, dan perairan yang jernih menciptakan satu habitat bagi berbagai jenis moluska (kerang), bintang laut, kepiting, anemon, dan juga ganggang laut. (Bengen, 2001). Parameter utama yang sangat mempengaruhi kondisi pantai berbatu adalah fenomena pasang, dinamikanya sangat berpengaruh terhadap biota yang menginginkan kondisi alam yang bergantian antara tergenang dan terbuka; gelombang, energi yang dihempaskan bisa merusak komunitas biota yang menempel di batu-batuan, terutama pada batu yang langsung menghadap ke laut (Dahuri et al., 1996).

\section{d. Wisata Pantai}

Wisata pantai adalah kegiatan wisata leisure dan aktifitas rekreasi yang dilakukan dikawasan pesisir dan perairannya (Bibin, 2018). Wisata pantai memiliki beberapa kategori kegiatan berwisata yaitu rekreasi pantai, dimana rekreasi pantai bertujuan untuk mencari kepuasan dan menghilangkan rasa stress dengan melakukan kegiatan bersantai di pantai (Nugraha et al. 2013). Wisata pantai kategori rekreasi merupakan jenis kegiatan yang paling dominan di daerah pantai dan kegiatan rekreasi memanfaatkan sumberdaya pantai seperti pasir putih, hamparan pantai, pemandangan (view), biota dan perairannya (Yulianda et al. 2010).

\section{e. Ekosistem Wilayah Pesisir}

Ekosistem wilayah pesisir yang merupakan suatu himpunan integral dari komponen hayati dan non-hayati, mutlak di butuhkan oleh manusia untuk hidup dan meningkatkan mutu kehidupan (Yulianda et al. 2010). Ekosistem pesisir dapat bersifat alami atau pun buatan, adapun ekosistem alami yang terdapat di wilayah pesisir antara lain: terumbu karang, hutan mangrove, padang lamun, pantai berpasir dan lain-lain. Sedangkan ekosistem buatan antara lain berupa: tambak, sawah pasang surut, kawasan pariwisata, kawasan industri, kawasan agroindustri dan kawasan pemukiman (Dahuri 2003). Sumberdaya alam pesisir memiliki potensi yang dapat dimanfaatkan untuk kepentingan wisata. Aktifitas wisata merupakan suatu bentuk pemanfaatan sumberdaya alam yang mengandalkan jasa alam untuk kepuasan manusia (Yulianda et al. 2010).

\section{f. Pengembangan Wisata Pantai Berkelanjutan}

Pengembangan ekowisata pesisir dan laut harus mempertimbangkan dua aspek, yaitu aspek tujuan wisata dan aspek pasar, namun pengembangan produk wisata tetap menjamin kelestarian sumberdaya alam dan 
budaya masyarakat pesisir dan laut (Tuwo, 2011). Strategi pengelolaan wisata yang berkelanjutan harus memenuhi empat aspek dalam implementasinya yaitu: (1) aspek ekologi, (2) aspek social, (3) aspek ekonomi dan (4) aspek kelembagaan (Bibin, Vitner, \& Imran, 2017). Pengelolaan berkelanjutan merupakan suatu strategi pengelolaan yang memberikan ambang batas pada laju pemanfaatan ekosistem alamiah danbuatan, serta sumberdaya alam yang ada di dalamnya (Tuwo, 2011).

\section{Metodologi Penelitian}

\section{a. Waktu dan Tempat Penelitian}

Penelitian dilaksanakan pada Maret sampai Mei 2019 di Kawasan Pesisir Pantai Songka Kelurahan Takkalala Kecamatan Wara selatan Kota Palopo.

\section{b. Pengumpulan Data}

Pengambilan data diperoleh dengan melakukan, wawancara mendalam (depth interview) menggunakan kuisioner dan dokumentasi. Penentuan responden dilakukan secara purposive sampling. Purposive sampling adalah tehnik pengambilan sampel sumber data dengan pertimbangan tertentu yakni sumber data dianggap paling tahu tentang apa yang diharapkan. Adapun responden yang sengaja dipilih dalam penelitian ini adalah 10 stakeholder terdiri dari pemerintah, lembaga swadaya masyarakat dan tokoh masyarakat.

\section{c. Analisis Hirarki Proses (AHP)}

Tehnik Analytical Hierarchy Process (AHP) mencakup penilaian secara sekaligus baik yang bersifat kualitatif maupun kuantitatif. Pada AHP, penetapan prioritas kebijakan dikakukan dengan menangkap secara rasional presepsi orang, kemudian mengkonversi faktor-faktor yang intangible (yang tidak terukur) kedalam aturan yang biasa, sehingga dapat dibandingkan. Metode yang dikembangkan oleh Thomas L. Saaty dapat membantu pengambil keputusan untuk menentukan kebijaksanaan yang akan diambil dengan menetapkan prioritas dan membuat keputusan yang paling baik ketika aspek kualitatif dan kuantitatif dibutuhkan untuk dipertimbangkan. Tahap paling awal dalam AHP adalah merinci permasalahan kedalam komponenkomponennya, kemudian mengatur bagian dari komponen-komponen tersebut kedalam bentuk hirarki. Hirarki paling atas diturunkan kedalam beberapa elemen set lainnya, sehingga pada akhirnya terdapat elemen-elemen yang spesifik atau elemen-elemen yang dapat dikendalikan (Saaty L., 1993).

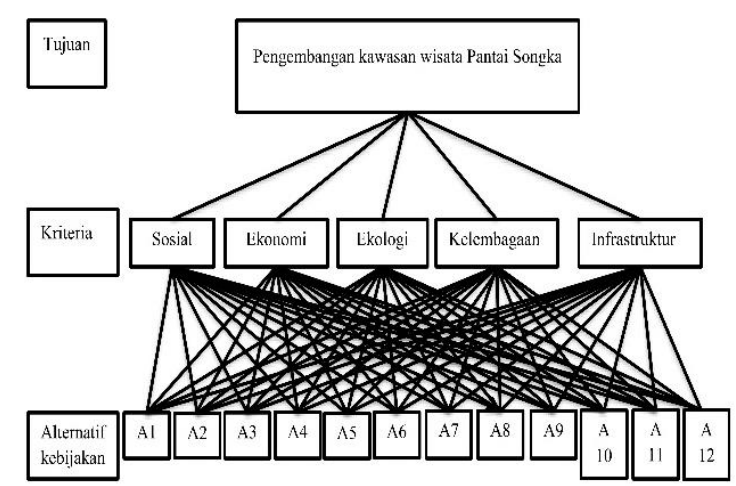

Sumber : (Saaty L., 1993).

Gambar 1. Hierarki penentuan strategi pengembangan wisata di kawasan Pantai Songka

\section{Hasil dan Diskusi}

a. Gambaran Umum Lokasi Penelitian Kelurahan Takkalala terletak di Kelurahan Wara Selatan. Secara geografis letak Kecamatan Wara Selatan sebelah Utara berbatasan dengan Kecamatan Wara dan Wara Timur, sebelah Timur berbatasan dengan Teluk Bone, sebelah Barat berbatasan dengan Kecamatan Sendana dan sebelah Selatan berbatasan dengan Kabupaten Luwu. Luas wilayah Kecamatan Wara Selatan adalah $10.66(\mathrm{~km}) 2$. Dari topografi wilayahnya seluruh kelurahan di Kecamatan Wara Selatan merupakan daerah pesisir (Statistik, 2018).

\section{b. Iklim dan Cuaca}

Kecamatan Wara Selatan memiliki iklim tropis, pada tahun 2017 
bulan Juni menjadi bulan dengan curah hujan tertinggi yaitu $362 \quad(\mathrm{~mm}) 3$ dengan jumlah hari hujan sebanyak 26 hari (Statistik, 2018).

c. Strategi pengembangan di Kawasan wisata Pantai Songka

Pemilihan strategi pengembangan kawasan wisata Pantai Songka dilakukan melalui analisis AHP dengan mensintesa kepentingan relatif antar elemen dalam hirarki AHP berupa kriteria serta alternatif kebijakan. Adapun urutan lengkap nilai bobot untuk kriteria serta alternatif kebijakan dapat dilihat pada (gambar 1).

\section{d. Penetapan Tujuan Kriteria}

Pengembangan daerah wisata menjadi kawasan wisata terintegrasi memiliki beberapa implikasi strategis, salah satunya dalam penambahan Pendapatan Asli Daerah (PAD), peningkatan kesejahteraan masyarakat sekitar, dan melestarikan sumberdaya. Strategi pegembangan harus mempertimbangkan berbagai kriteria penting seperti ekologi, ekonomi, sosial, kelembagaan dan infrastruktur dengan mempertimbangkan pendapat stakeholder yang terlibat dalam pengembangan wisata Pantai Songka di Kota Palopo yang berasal dari instansi pemerintah, kelompok masyarakat dan masyarakat.

e. Analisis Kriteria Pengembangan Wisata Pantai Songka

Berdasarkan hasil analisis AHP pengembangan wisata di Pantai Songka, kriteria yang menjadi prioritas utama adalah Ekologi (0.299), sosial (0.233), ekonomi (0.210), infrastruktur (0.151) dan kelembagaan (0.107). Secara lengkap urutan kriteria prioritas tersebut dapat dilihat pada Gambar 2.

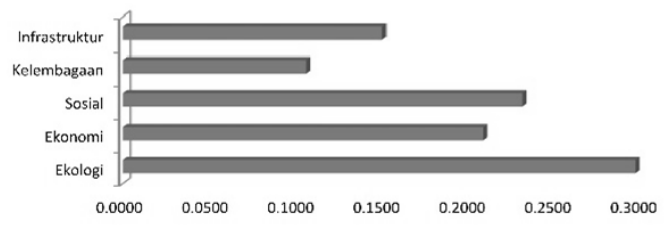

Sumber : Hasil olahan data primer, 2019

Gambar 2. Urutan kriteria prioritas pengembangan wisata di Pantai Songka
Berdasarkan perbandingan berpasangan kriteria ekologi menjadi prioritas utama. Kriteria ekologi merupakan persyaratan biofisik yang harus dipenuhi agar kegiatan wisata dapat didukung oleh lingkungan. Kriteria ekologi mencakup atribut kondisi perairan dalam hal ini kualitas air untuk aktifitas wisata bahari. Kriteria sosial mencakup atribut penyerapan tenaga kerja lokal. Kriteria ekonomi mencakup aspek pemasaran dan aspek nilai ekonomi. Kriteria ini mencakup atribut pendapatan asli daerah (PAD) dan pendapatan masyarakat. Kriteria kelembagaan mencakup atribut program pemberdayaan masyarakat, kerjasama serta menyusun kebijakan pengembangan wisata Pantai Songka. Kriteria infrastruktur mencakup sarana dan prasarana kawasan wisata dan kemudahan mengakses lokasi wisata.

f. Strategi Alternatif Pengembangan Wisata Pantai Songka

Berdasarkan analisis hirarki proses (AHP) secara lengkap urutan strategi prioritas pengembangan kawasan wisata Pantai Songka di Kota Palopo dapat dilihat pada gambar 3.

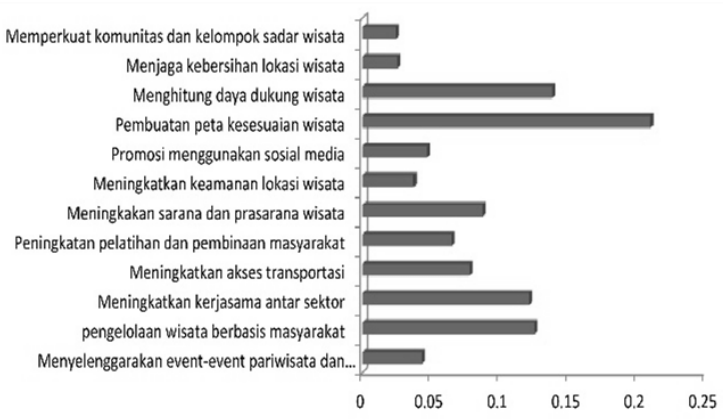

Sumber : Hasil olahan data primer, 2019

Gambar 3. Strategi alternatif pengembangan wisata di Pantai Songka

Fokus utama pada
prioritas pengembangan
kawasan
wisata Pantai Songka
pembuatan peta kesesuian
Strategi prisata.
menghitung daya dukung kawasan
wisata. Perlunya ada pembatasan
jumlah pengunjung yang ingin
berkunjung di kawasan wisata Pantai
Songka agar kelestarian sumberdaya


alam tetap terjaga dan tidak mengalami kerusakan. Menurut Yulianda et al (2007) dalam konteks wisata daya dukung kawasan merupakan jumlah wisatawan yang dapat diterima oleh suatu lokasi wisata tanpa ada perubahan negative pada lingkungannya. Starategi prioritas yang ketiga adalah pengelolaan kawasan wisata berbasis masyarakat. Masyarakat didalam destinasi wisata yang kemudian disebut masyarakat local mempunyai potensi beragam aktivitas yang dapat dikreasikan menjadi produk wisata. Masyarakat dengan pengetahuan dan kebijakan local akan lebih memahami produk wisata yang dikembangkan serta dampak yang ditimbulkan. Menurut Flanigan et al (2014) aspek penting dalam wisata berkelanjutan adalah penekanan kepada wisata berbasis masyarakat. Pendekatan ini lebih focus terhadap partisipasi masyarakat lokal dalam perencanaan dan pengembangan destinasi wisata.

Strategi Prioritas yang keempat adalah meningkatkan kerjasama antar sector. Kerjasama atau kolaborasi antar sektor tersebut langkah langkah untuk mewujudkan pengembangan kawasan wisata secara berkelanjutan yang bermanfaat bagi masyarakat. Menurut Iqbal dan Muhammad (2007) kerja sama yang efektif adalah salah satunya adalah melalui komunikasi yang efektif dan tukar menukar informasi secara terus menerus sehingga perbedaan-perbedaan antar individu dan bidang dapat diatasi dan akan membawa perubahan-perubahan kebijakan maupun penyesuaian program untuk masa mendatang. Strategi prioritas yang kelima adalah meningkatkan sarana dan prasarana wisata. Penyediaan sarana dan prasarana dasar merupakan kegiatan penting untuk memperkuat pengembangan kawasan wisata Pantai Songka. Starategi prioritas keenam adalah meningkatkan akses transportasi. Melalui peningkatan pelayanan transportasi diharapkan dapat mempermudah akses wisatawan menuju kawasan wisata serta mempercepat pertumbuhan pengembangan kawasan wisata. Yoeti (2008) mengatakan bahwa aksesibilitas ke daerah tujuan wisata (DTW) yang akan dikunjungi banyak mempengaruhi pilihan pengunjung.

Strategi prioritas ketujuh adalah peningkatan pelatihan dan pembinaan masyarakat. Sumberdaya manusia merupakan salah satu modal dasar dalam upaya pengembangan wisata. Menurut (Tuwo, 2011) sumber daya manusia dalam bidang wisata harus memiliki keahlian dan keterampilan untuk memberikan pelayanan wisata serta dapat menangani berbagai masalah dalam berwisata dan berbagai persoalan yang ada. Strategi prioritas kedelapan adalah promosi wisata menggunakan social media dengan tujuan memperkenalkan objek wisata Pantai Songka diseluruh wilayah Indonesia dan seluruh dunia. Strategi prioritas kesembilan adalah menyelenggarakan event-event wisata dengan tujuan memperkenalkan atau mempromosikan potensi wisata di Kota Palopo khususnya wisata Pantai Songka. Starategi prioritas pengembangan kesepuluh adalah meningkatkan keamanan lokasi wisata. Faktor keamanan merupakan factor penting dalam pengembangan kawasan wisata, apabila lokasi wisata aman pengunjung mendapatkan kenyamanan selama berada dilokasi kawasan wisata. Starategi prioritas pengembagan kesebelas adalah menjaga kebersihan lokasi wisata. Apabila lokasi wisata terjaga kebersihannya pengunjung menjadi nyaman dan betah berada di lokasi wisata Pantai Songka. Strategi prioritas pengembangan yang terakhir adalah memperkuat komunitas dan kelompok sadar wisata.

\section{Kesimpulan}

Berdasarkan analisis hirarki proses (AHP) kriteria ekologi yang menjadi prioritas pertama dalam pengembangan kawasan wisata Pantai Songka adalah kegiatan wisata yang dapat didukung oleh lingkungan. Strategi pengembangan yang menjadi 
prioritas adalah pembuatan peta kesesuaian wisata Pantai Songka dan menghitung daya dukung kawasan wisata dengan tujuan agar ada pembatasan jumlah pengunjung yang ingin berkunjung di kawasan wisata Pantai Songka sehingga kelestarian sumberdaya alam tetap terjaga dan tidak mengalami kerusakan.

\section{References}

[1] Bibin, M. (2018). Pengembangan Wisata Bahari Secara Berkelanjutan (Studi Kasus Pantai Labombo Kota Palopo Provinsi Sulawesi Selatan). Institut Pertanian Bogor.

[2] Bibin, M., Vitner, Y., \& Imran, Z. (2017). Analisis Kesesuaian dan Daya Dukung Wisata Kawasan Pantai Labombo Kota Palopo. Jurnal Pariwisata, IV(2), 94-102.

[3] Christopher, L. (2011). Service Marketing in Asia 2nd (Vol. 3). New Jersey: Pearson Educational International.

[4] Saaty L., T. (1993). Pengambilan Keputusan Bagi Para Pemimpin. Proses Hierarki Analitik untuk Pengambilan Keputusan Dalam Situasi Yang Kompleks. Jakarta: Pustaka Binaman Pressindo.

[5] Statistik, B. P. (2018). Kecamatan Wara Dalam Angka 2018.

[6] Tuwo, A. (2011). Pengelolaan Ekowisata Pesisir dan Laut (Pendekatan Ekologi, Sosial-Ekonomi, Kelembagaan dan Sarana Wilayah. Sidoarjo: Brilian Internasional.

[7] Yoeti OA. 2008. Pemasaran Pariwisata. Jakarta (ID): Angkasa. $240 \mathrm{hlm}$.

[8] Yulianda F. 2007. Ekowisata bahari sebagai alternatif pemanfaatan sumberdaya pesisir berbasis konservasi. Seminar sains 21 Februari 2007 pada Departemen Manajemen Sumberdaya Perairan. Bogor (ID): Fakultas Perikanan dan Ilmu Kelautan. Institut Pertanian Bogor.

[9] Yulianda F, Fahrudin A, Hutabarat AA, Harteti S, Kusharjani, Kang HS, 2010. Pengelolaan pesisir dan laut secara terpadu. Bogor (ID). Pusdiklat Kehutanan Departemen Kehutanan RI, SECEM-Korea Internasional Cooperation Agency. 